\title{
REFLEXÕES SOBRE O CURRÍCULO INTEGRADO NA EDUCAÇÃO PROFISSIONAL E TECNOLÓGICA: DESAFIOS E POSSIBILIDADES
}

\author{
Wallace Pereira Sant Ana*, Sara Maria Souza Nogueira, Wanderley Azevedo de Brito \\ *E-mail: wallacegilvania@hotmail.com \\ Instituto Federal de Educação, Ciência e Tecnologia de Goiás \\ DOI: $10.15628 /$ rbept.2020.8813
}

Artigo submetido em jul/2019 e aceito em fev/2020

\begin{abstract}
RESUMO
O presente artigo faz um exercício de reflexão científica sobre o currículo integrado na educação profissional e tecnológica. A partir de uma revisão de literatura, dialogamos acerca de uma concepção de ensino que supere a dualidade existente na educação brasileira, decorrente de aspectos históricos e culturais. É possível compreender ao longo dessa discussão a origem, os princípios, os objetivos e as bases conceituais do currículo integrado na educação profissional e tecnológica, o que nos possibilita evidenciar alguns desafios e possibilidades para a consolidação de práticas educativas mais críticas e coerentes, e de uma reflexão sobre o currículo integrado enquanto elemento norteador da formação omnilateral e politécnica.
\end{abstract}

Palavras-Chave: Currículo Integrado. Educação Profissional e Tecnológica. Desafios. Possibilidades.

\section{REFLECTIONS ON THE INTEGRATED CURRICULUM IN PROFESSIONAL AND TECHNOLOGICAL EDUCATION: CHALLENGES AND POSSIBILITIES}

\begin{abstract}
The present article makes an exercise of scientific reflection on the integrated curriculum in professional and technological education. From a literature review, we talk about a conception of education that surpasses the duality existing in Brazilian education, due to historical and cultural aspects. It is possible to understand throughout this discussion the origin, principles, objectives and conceptual bases of the integrated curriculum in vocational and technological education, which enables us to highlight some challenges and possibilities for the consolidation of more critical and coherent educational practices, and of reflection on the integrated curriculum as a guiding element of omnilateral and polytechnic education..
\end{abstract}

Keywords: Integrated Curriculum. Professional and Technological Education. Challenges. Possibilities. 


\section{INTRODUÇÃO}

A produção teórica sobre a temática "Currículo Integrado" ou "Integração Curricular" tem ganhado destaque no cenário nacional, principalmente na última década, após a expansão da rede federal de ensino, a partir da Lei $n^{\circ} 11.892$, de 29 de dezembro de 2008, a qual instituiu a Rede Federal de Educação Profissional, Científica e Tecnológica, criando os Institutos Federais de Educação, Ciência e Tecnologia.

Ressalta-se também outros elementos normativos que tratam tópicos relacionados à integração curricular no ensino médio, como as Diretrizes Curriculares Nacionais para a Educação Básica (2010), as Diretrizes Curriculares Nacionais para o Ensino Médio (2012) e as Diretrizes Curriculares Nacionais para a Educação Profissional Técnica de Nível Médio (2012).

A crise de identidade do ensino médio é abordada por vários estudiosos, como Frigotto, Ciavatta e Ramos (2005) e Saviani (1989), os quais apresentam alguns questionamentos quanto aos objetivos desta etapa da educação, a saber: deve formar técnicos de nível médio especializados ou politécnicos? Preparar mão-de-obra para o mercado de trabalho ou cidadãos capazes de atuar ativamente no mercado de trabalho? Como encontrar equilíbrio entre formação geral, humanística e técnica? O ensino médio deve ser unitário ou diferenciado?

A partir do exposto, apresentaremos uma reflexão sobre o currículo integrado na educação profissional e tecnológica (EPT). Destacamos alguns temas, como a dualidade educacional e os aspectos históricos e culturais decorrentes dos processos de organização curricular na EPT; a origem, os princípios, os objetivos e as bases conceituais do currículo integrado, e, a partir daí, evidenciar alguns desafios e possibilidades que se tem percebido no contexto da EPT pata consolidação de práticas educativas e de uma formação omnilateral e politécnica.

\section{METODOLOGIA}

Inicialmente, para o delineamento da pesquisa, realizou-se um levantamento bibliográfico, a fim de apresentar a revisão de literatura a respeito do currículo integrado no Ensino Médio Integrado e seus desdobramentos no que se refere ao conceito, origem e contradições.

A revisão de literatura é momento em que o pesquisador "reporta e avalia o conhecimento produzido em pesquisas prévias, destacando conceitos, procedimentos, resultados, discussões e conclusões relevantes para seu trabalho" (PRODANOV; FREITAS, 2013, p. 79). Ainda conforme os autores a revisão de literatura cumprem o papel de informar "[...] quem já escreveu e o que já foi publicado sobre o assunto, que aspectos já foram abordados, quais as lacunas existentes na literatura" (PRODANOV; FREITAS, 2013, p. 78). 
Para além da revisão narrativa, foi realizada a revisão sistemática no Portal da Capes com filtro nos últimos 5 anos e limitados aos artigos em português. A realização da pesquisa deu-se no início de dezembro de 2018, realizada em bibliotecas virtuais, tendo sido selecionados os principais trabalhos dedicados a reflexões sobre o currículo do ensino médio integrado quanto aos desafios e possibilidades na educação Profissional e tecnológica.

Após a conclusão do levantamento dos dados na revisão de literatura, a sistematização e interpretação destes foi realizada por meio de análise de conteúdo.

Considera-se análise de conteúdo:

Um conjunto de técnicas de análise das comunicações visando obter, por procedimentos, sistemáticos e objetivos de descrição do conteúdo das mensagens, indicadores (quantitativos ou não) que permitam a inferência de conhecimentos relativos às condições de produção/recepção (variáveis inferidas) destas mensagens (BARDIN, 1977, p. 42).

Quanto aos objetivos, a pesquisa é do tipo explicativa, pois identifica os fatores que determinam ou que contribuem para a ocorrência dos fenômenos (GIL, 2002). Quanto à abordagem, trata-se de uma pesquisa qualitativa que analisa os aspectos subjetivos e objetivos que qualificam 0 problema.

No presente estudo, portanto, optou-se pela modalidade de pesquisa qualitativa como percurso metodológico para a revisão de literatura. Gil (2002, p. 94) corrobora, dizendo que "métodos de pesquisa qualitativa estão voltados para auxiliar os pesquisadores a compreenderem pessoas e seus contextos sociais, culturais e institucionais".

Esta pesquisa baseia-se na dialética que, por sua vez, tem como fundamento o materialismo histórico. O materialismo histórico é consolidado como "a ciência filosófica do marxismo que estuda as leis sociológicas que caracterizam a vida da sociedade, de sua evolução histórica e da prática social dos homens, no desenvolvimento da humanidade" (TRIVIÑOS, 1987, p. 51).

Esta dialética, consubstancia-se na análise crítica das contradições para tentar entender a essência de um determinado fenômeno. Sua fundamentação se baseia na tríade tese-antítese-síntese, que compõe os pilares que norteiam a compreensão da contradição, inerentes ao próprio processo de formação do fenômeno humano de forma a sinalizar e compreender as leis que regem, social e culturalmente, a sociedade e as atividades advindas do desenvolvimento histórico-social e cultural do indivíduo. 


\section{CURRÍCULO INTEGRADO NA EDUCAÇÃO PROFISSIONAL E TECNOLÓGICA: REVISÃO DE LITERATURA}

Os questionamentos relacionados ao processo de formação dos estudantes no ensino médio na EPT são pertinentes e traz à reflexão uma proposta de educação que privilegie a construção de uma escola única, integral e integrada ao ensino médio, pois, como afirma Frigotto, Ciavatta e Ramos (2005, p. 45) a integração geral e técnica no ensino médio "[...] é condição necessária para a travessia em direção ao ensino médio politécnico e à superação da dualidade educacional brasileira pela superação da dualidade de classes".

Uma escola unitária com currículo integrado está diretamente ligada às concepções da "escola politécnica". Esse modelo de escola fundamenta-se em um ensino médio politécnico ou tecnológico e é considerado o caminho para a formação humana nas instituições de educação profissional técnica de nível médio.

O termo "politécnica", conhecido atualmente como educação tecnológica, tem como força produtiva a presença da ciência e da tecnologia, e pretendia, como diz Saviani (1989, p. 13), à "superação da dicotomia entre trabalho manual e trabalho intelectual, entre instrução profissional e instrução geral".

Saviani ainda complementa a formação humanizada a partir da compreensão do conceito de politecnia:

A noção de politecnia diz respeito ao domínio dos fundamentos científicos e das diferentes técnicas que caracterizam o processo de trabalho moderno. Diz respeito aos fundamentos das diferentes modalidades de trabalho. Politecnia, nesse sentido, se baseia em determinados princípios, determinados fundamentos e a formação politécnica deve garantir 0 domínio desses princípios, desses fundamentos (SAVIANI, 1989, p. 17).

O conceito de politecnia foi criado Karl Marx em meados do século XIX durante o período da Revolução Industrial na Inglaterra (1780). O sociólogo alemão buscou compreender e intervir naquela nova realidade, a partir desse conceito inovador, que vai, além de integrar-se com as imposições da revolução, compreender a educação em dois planos: da filosofia, da política e do socialismo; e das implicações das indústrias na vida dos trabalhadores e das crianças.

Politecnia é um conceito que tem sido trabalhado principalmente por autores ligados ao campo da Educação e Trabalho, está associada a uma perspectiva de Educação Integrada e tem sido usada como contraponto à pedagogia das competências. Ao contrário do que muitos pensam, a politecnia não é sinônimo de "ensino de muitas técnicas" ou de polivalência, mas significa "uma educação que possibilita a compreensão dos princípios científico-tecnológicos e históricos da produção moderna, de modo a orientar os estudantes à realização de múltiplas escolhas" (RAMOS, 2008, p. 3). 
Antônio Gramsci, comunista italiano, também buscou fundamentar seus estudos em busca da superação da dicotomia entre cultura geral e cultura técnica nos processos de ensino e aprendizagem vivenciados nas instituições educacionais de forma fragmentada e positivista.

Nessa perspectiva, as discussões em relação a EPT, dentre eles o currículo integrado, quanto ao conceito e origem, faz-se pertinente, pois além de ser abordado o Currículo Integrado, serão enfatizados outros conceitos inerentes à EPT e que se entrelaçam entre si: politecnia, interdisciplinaridade e transversalidade.

Currículo integrado tem como objetivo compreender o conhecimento a partir do viés de uma visão global, promovendo a interdisciplinaridade. Sabese que as matrizes curriculares dos cursos técnicos integrados ao Ensino Médio dos Institutos Federais de Educação, Ciência e Tecnologia são constituídas de três bases: Base Nacional Comum (ciências exatas, ciências da natureza, ciências humanas, linguagens e matemática); Núcleo Diversificado; e Educação Profissional (disciplinas técnicas).

A partir início do último século, mas especificamente no ano de 2004, após vários debates e produções acadêmicas em torno do currículo integrado, a temática ganha forma com a promulgação do Decreto-Lei $n^{\circ}$ 5.154, de 23 de julho de 2004, estabelecendo novamente a possibilidade de oferta integrada do ensino técnico com a educação básica. As instituições de ensino são desafiadas a colocar em prática a integração curricular, por meio de uma didática voltada à formação omnilateral dos educandos.

Sacristán (2000, p. 16) conceitua currículo como "[...] uma prática na qual se estabelece um diálogo, por assim dizer, entre agentes sociais, elementos técnicos, alunos que reagem frente a ele, professores que o modelam, etc". Assim, currículo é uma prática que estabelece a função socializadora de cada instituição, expressando-se por intermédio de diversas práticas, dentre elas as práticas pedagógicas, voltadas ao ensino. É construído através de um projeto ou plano ordenado por determinados princípios, que agregam valores e tornam a instituição peculiar em relação às outras.

Em relação ao conceito de integrar (integração), não podemos nos prender aos conceitos morais do sentido da palavra, como tornar íntegro, inteiro. O termo deve ser compreendido em sua completude, como as partes no seu todo, a unidade no diverso, onde a educação é tratada como em sua totalidade social, desde suas mediações históricas até a concretização dos processos educativos.

No caso da formação integrada ou do ensino médio integrado ao ensino técnico, queremos que a educação geral se torne parte inseparável da educação profissional em todos os campos onde se dá a preparação para o trabalho [...] (CIAVATTA, 2005, p. 84).

Ao longo do último século, foram realizados vários estudos com o objetivo de refletir acerca da fragmentação dos conhecimentos e da falta de 
integração entre currículo e cotidiano, em virtude da implantação de novos padrões de produção e trabalho que tornaram o conhecimento ainda mais fragmentado. Para superar essa dissociação educacional, foi criado por Antônio Gramsci, o conceito "Currículo Integrado". Esse autor, no período em que ficou preso, escreveu a obra Cadernos do Cárcere, a qual criticava duramente o modelo de educação vigente na Itália, propondo o conceito de "Escola Unitária" e aprofundando o conceito de Politecnia.

\begin{abstract}
Uma formação nessa perspectiva, tem seus princípios na "Escola Unitária" de Gramsci, que visa formar os trabalhadores de maneira integral, instrumentalizando-os para o exercício da profissão e o domínio das técnicas, dando-lhes acesso ao conhecimento geral produzido pela humanidade e preparando-os para serem os novos dirigentes da sociedade (RESENDE et al., 2017, p. 151;152).
\end{abstract}

O conceito de Escola Unitária foi criado por Gramsci a partir da divisão da escola que se vivenciava no contexto social e educacional da época. Existiam dois tipos de escolas, a clássica e a profissional, na qual a primeira destinavase às classes dominantes e aos intelectuais e a segunda às classes instrumentais, para o desenvolvimento de bases industriais na cidade, ou seja, destinava-se à formação de mão-de-obra para o trabalho manual nas indústrias.

A Revolução Industrial no Brasil ocorrida no início do século XX, que culminou com o êxodo rural, implicou na busca de um novo intelectual urbano. Criou-se então a escola técnica, que, ao lado da escola clássica, destruiu o princípio da orientação da cultura geral e da escola desinteressada e formativa. No entanto, conservou-se esse novo modelo apenas às pequenas elites dominantes, que deveriam difundir as escolas profissionais especializadas, responsáveis por preparar os alunos para desenvolver atividades predeterminadas.

A crise terá uma solução que, racionalmente, deveria seguir esta linha: escola única inicial de cultura geral, humanista, formativa, que equilibre equanimamente o desenvolvimento da capacidade de trabalhar manualmente (tecnicamente, industrialmente) e o desenvolvimento das capacidades de trabalho intelectual. Deste tipo de escola única, através de repetidas experiências de orientação profissional, passar-se-á a uma das escolas especializadas ou ao trabalho produtivo (GRAMSCI, 1982, p. 118).

A separação de escolas acarretava na desigualdade social, onde uma visava à formação do técnico intelectual, que detém o conhecimento necessário sobre determinada área, e a outra constituía o profissional para exercer a mão-de-obra manual e técnica. 


\section{RESULTADOS E DISCUSSÕES}

A partir do exposto, podemos perceber que diversos são os desafios e as perspectivas da implementação do Currículo Integrado na Educação Profissional e Tecnológica na perspectiva da práxis pedagógica omnilateral e politécnica.

O principal refere-se a reflexão em torno da efetivação dos princípios preconizados pelo currículo para além da unidade teoria e prática no que se refere aos conceitos, origem e os desafios para a efetivação de práticas significativas e coerentes.

Outro consiste na análise das possibilidades de sua efetivação de forma a consolidar a formação crítica e reflexiva do ser de forma omnilateral. Nesse sentido, Marx defende que essência pedagógica deve primar pela instrução intelectual, física e tecnológica, elucidando a necessidade de se efetivar uma escola pública, gratuita, laica e integrada para todos, sem distinções.

Neste enlear, o trabalho enquanto princípio educativo se articula em três dimensões: a comunicação/expressão, a produção e a fruição. A interação física e espiritual do homem com a natureza e com outros homens pela comunicação e expressão é o fator que promove a aprendizagem para 0 trabalho, comunicação, produção e consumo.

Observa-se, então, que há uma classificação e subdivisão das matrizes curriculares, seja de disciplinas, de bases ou de núcleos, o que retrata como a ciência se desenvolveu ao longo dos tempos, diversificando-se e sendo segmentada, promovendo um alto grau de classificação. Nesse período histórico, os currículos foram fragmentados, sendo esse tipo de currículo praticado no cotidiano escolar. As principais características de um currículo fragmentado são o alto nível de classificação, o isolamento dos conteúdos das disciplinas,

No entanto, existem outras formas de praticar o currículo. O Currículo Integrado surge nesse contexto como uma proposta que pode contribuir para a integração entre as disciplinas e promover a interdisciplinaridade. Essa perspectiva de integração curricular tem como foco a redução dos níveis de classificação, através da integração desses conhecimentos, onde o currículo não é concebido por disciplinas isoladas, mas por meio de áreas do saber, pois o conhecimento é global, constituído por vários saberes.

\section{CONSIDERAÇÕES FINAIS}

A proposta de uma análise acerca das possibilidades e desafios do currículo integrado na Educação Profissional e tecnológica vislumbrada historicamente decorre de aspectos históricos e ontológicos que por sua vez representam dualidades e perspectivas existentes no de ensinoaprendizagem no cenário educacional brasileiro. 
Para tanto percebe-se que as concepções presentes na escola dualista por sua vez negam a formação integral que tanto se preconiza no currículo integrado, pois este deve aspirar a formação crítica e reflexiva do ser de maneira omnilateral e assim preparando o indivíduo para o mundo do trabalho.

As reflexões elencadas ao longo deste artigo perspectiva fundamentalmente um olhar acerca dos desafios que ainda são evidenciados na Educação Profissional e Tecnológica que por ora reclama por mudanças para além da formação teórica, primando pela formação integral e politécnica.

\section{REFERÊNCIAS}

BARDIN, L. Análise de conteúdo (L. de A. Rego \& A. Pinheiro, Trads.). Lisboa: Edições 70. 2006. (Obra original publicada em 1977).

CIAVATTA, Maria. A formação de professores para a Educação Profissional e Tecnológica: perspectiva histórica e desafios contemporâneos. Anais e Deliberações XVI ENDIPE - Encontro Nacional de Didática e Práticas de Ensino - UNICAMP - Campinas - 2012 Junqueira \& Marin Editores Livro 2 - p.002122 12 - I Conferência Nacional de Educação Profissional e Tecnológica. - Brasília: Ministério da Educação, Secretaria de Educação Profissional e Tecnológica. 2007.

FRIGOTTO, Gaudêncio; CIAVATTA, Maria; RAMOS, Marise, (orgs). Ensino Médio Integrado: Concepção e Contradições. São Paulo: Cortez, 2005a.

GIL, A. C. Como elaborar projetos de pesquisa. 4. ed. São Paulo: Atlas, 2002.

GRAMSCI, Antônio. Os intelectuais e a organização da cultura. Trad. Carlos Nelson Coutinho. Rio de Janeiro, Civilização Brasileira, 1982.

PRODANOV, Cleber Cristiano; FREITAS, Ernani Cesar de. Metodologia do trabalho científico: métodos e técnicas da pesquisa e do trabalho acadêmico. 2. ed. Novo Hamburgo: FEEVALE, 2013.

RAMOS, Marise N. Possibilidades e Desafios na Organização do Currículo Integrado. In: In: RAMOS, Marise N. (Org.); FRIGOTTO, Gaudêncio (Org.); CIAVATTA, Maria (Org.) Ensino Médio Integrado: Concepção e Contradições. 1. ed. São Paulo: Cortez, 2005.

RAMOS. Concepção do Ensino Médio Integrado. 2008. Disponível em: $<$ http://forumeja.org.br/go/sites/forumeja.org.br.go/files/concepcao_do_ensino _medio_integrado5.pdf>. Acesso em 16.12.2019.

RESENDE, Eduardo Pereira, et al. Programa de formação pedagógica: organização do trabalho pedagógico e integração curricular. Goiânia: IF Goiano, 2017. 
SACRISTÁN, José Gimeno. O currículo uma reflexão sobre a prática. Porto Alegre: Artmed, 2000.

SAVIANI, D. Sobre a concepção de Politecnia. Apresentado durante os trabalhos do "Seminário Choque Teórico", realizadono Politécnico da Saúde Joaquim Venâncio, da Fundação Oswaldo Cruz, nos dias 2, 3 e 4 de dezembro de 1987. Rio de Janeiro, 1989.

TRIVIÑOS, Augusto Nibaldo Silva. Introdução à pesquisa em ciências sociais: a pesquisa qualitativa em educação. São Paulo: Atlas, 1987. 